\title{
Relevance of Heat-Shock Protein 70 Expression as Histological Marker of Paraquat-Induced Damage to Rat Liver Cells
}

\author{
Shin-ichi Kubo ${ }^{1}$, Itsuo Tokunaga ${ }^{1}$, Atsuko Yamamoto $^{1}$, Takako Gotohda ${ }^{1}$ and \\ Kyoji Morita ${ }^{2}$ \\ ${ }^{1}$ Department of Legal Medicine, ${ }^{2}$ Department of Pharmacology, The Tokushima University School of Medicine, \\ Kuramoto, Tokushima 770-8503
}

Received November 27, 1998; accepted August 17, 1999

\begin{abstract}
Heat-shock protein 70 (HSP70) is expressed in response to various stressful stimuli, and generally used as a histological marker of cell damage. While paraquat has previously been shown to cause HSP70 expression as a result of the oxidative cell damage, recent study has shown that HSP70 expression induced by paraquat poisoning is no longer observed at $18 \mathrm{hr}$ after the drug administration in the senescence-accelerated mouse liver, thereby raising the question whether the cell damage is always accompanied by elevated HSP70 expression. To affirm the relevance of HSP70 expression as a marker of the cell

reactivity and lipid peroxidation in paraquatpoisoned rat liver were examined. The immunostaining of HSP70 was still clearly detected at $24 \mathrm{hr}$ after the drug administration. Lipid peroxidation, a biochemical maker of the oxidative cell damage, was also elevated by the same treatment, suggesting that the expression of HSP7O immunoreactivity observed here may reflect the oxidative-damage to liver cells. These results seem to provide evidence supporting the relevance of HSP70 expression as a histological marker of paraquat-induced damage to rat liver cells.
\end{abstract} damage, the expression of HSP70 immuno-

Key words: HSP70 expression, Histological marker, Paraquat treatment, Oxidative damage, Rat liver

\section{Introduction}

Heat-shock protein 70 (HSP70) is originally identified as a member of the inducible protein family in response to thermal stress, and later shown to be induced by various types of chemical and physical stimuli, such as oxidative, excitotoxic and osmotic stresses $[2,8,9,11,13,14]$. Since HSP70 is expressed in damaged but still viable cells, the expression of this heat-inducible protein is generally used as a histological marker of cell damage invarious tissues [4, $5,12,15]$. Actually, the immunochemical detection of HSP70 expression is considered to be the most popular and convenient method for determining the cell damage, and there levance of HSP70 expression as a marker of cell damage is considered to be well established. However, recent study has shown that the elevation of HSP70 levels in the senescence-accelerated mouse liver is observed shortly after the administration of paraquat (approximately

Correspondence to: Dr. Shin-ichi Kubo, Department of Legal Medicine, The Tokushima University School of Medicine, 03-18-15 Kuramoto, Tokushima 770-8503, Japan.
3-12 hr), but no longer observed at $18 \mathrm{hr}$ or later [10], thereby proposing the possibility that the elevation of HSP70 expression is not always detectable in the cells receiving the damage. Therefore, it seems still open to discussion whether HSP70 expression is completely reliable as a marker of cell damage under any circumstances.

Paraquat $\left(1,1^{\prime}\right.$-dimethyl-4,4'-bipyridinium), a nonselective contact herbicide, has previously been shown to cause the oxidative damage to the DNA in various rat organs [16]. To further investigate the toxic effect of paraquat on the brain, we have employed HSP70 expression as one of the markers of the damage to neurons and glial cells, and examined the expression of HSP70 immunoreactivity in rat hippocampus at $24 \mathrm{hr}$ after the drug administration. In these studies, paraquat administration was shown to induce the expression of HSP70 immunoreactivity in neuronal and glial cells, thus suggesting that paraquat may cause the damage to both hippocampal neurons and glial cells in the rat brain [6]. However, to ascertain the credibility of these histological findings, it is still necessary to reaffirm the relevance of HSP70 expression as a marker of the cell damage. For this 
purpose, we examined the effect of paraquat poisoning on lipid peroxidation, a biochemical marker of oxidative cell damage, as well as HSP70 expression in rat liver, and found that HSP70 immunoreactivity was still clearly detected at $24 \mathrm{hr}$ after the drug administration, and that this expression was accompanied by lipid peroxidation, thus providing evidence supporting the relevance of HSP70 expression as a histological marker of the paraquatinduced damage to rat liver cells.

\section{Materials and Methods}

\section{Tissue preparation and immunohistochemical staining}

Male Wistar rats weighing 180-200 g were obtained from Japan SLC (Shizuoka, Japan), and maintained on a $12 \mathrm{hr}$ light-12 hr dark lighting schedule for a week with food and water available ad libitum. Paraquat dichloride (Aldrich Chemical Co., Milwaukee, WI) was dissolved in saline, and infected intraperitoneally. At $24 \mathrm{hr}$ after the administration, animals were perfused through the ascending aorta with phosphate buffered saline (PBS) followed by $4 \%$ paraformaldehyde in $0.1 \mathrm{M}$ phosphate buffer ( $\mathrm{pH}$ 7.2) under anesthesia (sodium pentobarbital, $50 \mathrm{mg} / \mathrm{kg}$, i.p.), and the liver was disected out and postfixed in the same fixative overnight at $4{ }^{\circ} \mathrm{C}$. The tissue was then embedded in paraffin, and $5 \mu \mathrm{m}$-thick sections were made using a sliding microtome.

Sections were dewaxed with xylene, rinsed with PBS, and endogenous peroxidase activity was quenched by incubating wity $3 \%$ hydrogen peroxide in PBS for $5 \mathrm{~min}$. They were incubated with either a mouse monoclonal anti-ubiquitin antibody (1 : 500; Amersham, Buckinghamshire, England) or a rabbit polyclonal anti-ubiquitin antibody (1:100; Dako Corp., Carpinteria, CA) for $1 \mathrm{hr}$ at $37^{\circ} \mathrm{C}$, and the immunostaining was carried out using LSAB2 kit/HRP (Dako Corp., Carpinteria, CA) following the manufacture's instruction (incubating with the mixture of biotinylated goat anti-mouse IgG and biotinylated goat anti-rabbit IgG antibodies for $30 \mathrm{~min}$, followed by incubation with horseradish peroxidaselabelled streptoavidin for $15 \mathrm{~min}$ ). The immunostaining was visualized by incubating in the reaction mixture containing 0.02\% 3,3'-diaminobenzidine (DAB) and 0.03\% hydrogen peroxide in PBS. The coverslip was mounted on a glass slide, and then examined and photographed.

\section{Determination of lipid peroxidation}

Animals were treated with paraquat as described above, and sacrificed by decapitation at $24 \mathrm{hr}$ after the drug administration. Liver was dissected out, and immediately frozen in liquid nitrogen. Frozen tissue was homogenized in 5-volume of double-distilled water, and the homogenate was filtered through 4 layers of cheese cloth to remove unbroken tissue. An aliquot $(0.1 \mathrm{ml})$ of the homogenate was used for the analysis of lipid peroxidation. The stimulation of lipid peroxidation was determined by a thiobarbituric acid method as described previously [18]. Lipid peroxidation was expressed as the amount of thiobarbituric acid-reactive substances in the homogenate, and the values were normalized relating to wet weight of the tissue. Paraquatinduced lipid peroxidation was expressed as the percent of control.

\section{Determination of HSP70 $m R N A$}

Total RNA was prepared from frozen tissue by a single-step purification method [1]. Briefly, tissue was homogenized in 10 volumes of denaturing solution $[4 \mathrm{M}$ guanidinium thiocyanate, $0.1 \mathrm{M} 2$-mercaptoethanol, $0.5 \%$ $\mathrm{N}$-lauroylsarcosine, and $25 \mathrm{mM}$ sodium citrate, $\mathrm{pH} 7.0$ ]. Tissue homogenates were extracted with the same volume of phenol-chloroform $(2.5: 1)$, and the RNA precipitated with isopropanol. The phenol-chloroform extraction and isopropanol precipitation were repeated once, and the RNA pellet was washed with $75 \%$ ethanol, dried under vacuum, and then dissolved in sterile RNasefree water.

HSP70 mRNA levels were determined by a one-step RT-PCR method using total RNA as a template. Target RNA was reverse transcribed and amplified in $25 \mu \mathrm{l}$ of $1 \times$ first strand buffer $[75 \mathrm{mM} \mathrm{KCl}, 3 \mathrm{mM} \mathrm{MgCl}$, and $50 \mathrm{mM}$ Tris-HCl, $\mathrm{pH}$ 8.3] containing $500 \mu \mathrm{M}$ dNTPs, $400 \mu \mathrm{M}$ dithiothreitol, $5 \%$ dimethylsulfoxide, 25 pmoles of the G3PDH primer set (Clontech, Palo Alto, CA) and 25 pmoles of the HSP70 primer set using 100 units of M-MLV reverse transcriptase (Gibco BRL, Rockville, MD) and 2.5 units of recombinant Taq DNA polymerase (Gibco BRL, Rockville, MD). The reaction was carried out in an automated DNA thermal cycler (Gene ATAQ Controller, Pharmacia LKB, Uppsala, Sweden) as follows: 1) reverse transcription - primer annealing at $65^{\circ} \mathrm{C}$ for $10 \mathrm{~min}$, reverse transcription at $42^{\circ} \mathrm{C}$ for $20 \mathrm{~min}$, reverse transcriptase inactivation at $95^{\circ} \mathrm{C}$ for $4 \mathrm{~min}$, and 2) DNA amplification -30 cycles of DNA polymerase chain reaction with each cycle including denaturation at $95^{\circ} \mathrm{C}$ for $1 \mathrm{~min}$, primer annealing at $54^{\circ} \mathrm{C}$ for $1.5 \mathrm{~min}$, primer extension at $72^{\circ} \mathrm{C}$ for $1.5 \mathrm{~min}$, and a final extension step at $72^{\circ} \mathrm{C}$ for 5 min. The PCR products $(320 \mathrm{bp}$ fragment derived from the target HSP70 mRNA and $452 \mathrm{bp}$ fragment from the internal standard G3PDH mRNA) were separated on a $1 \%$ agarose gel containing $0.5 \mu \mathrm{g} / \mathrm{ml}$ of ethidium bromide in $1 \times$ TAE ( $40 \mathrm{mM}$ Tris-acetate, $\mathrm{pH} 8.0$, and $2 \mathrm{mM}$ EDTA). The agarose gel was photographed and the densitometric analysis was performed using NIH image 1.61 software, and HSP70 mRNA levels were expressed relative to G3PDH mRNA levels.

The primers specific for rat HSP70 gene were designed based on its published cDNA sequence [3, 7], and commercially synthesized by Amersham Pharmacia Biotech (Tokyo, Japan). The G3PDH primer set was obtained from Clontech (Palo Alto, CA). The sequences of these primers were as follows: upstream primer, $5^{\prime}$-AAGGTGGAGATCATCGCCAA- $3^{\prime}$ and downstream primer, $5^{\prime}$ GCGATCTCCTTCATCTTGGT-3' for HSP70 mRNA; 
upstream primer, 5'-ACCACAGTCCATGCCATAAC-3' and downstream primer, $5^{\prime}$-TCCACCACCCTGTTGCTGTA-3' for G3PDH mRNA.

\section{Data analysis}

Data were analyzed by analysis of variance (ANOVA) followed by Tukey's post hoc test, and presented as the mean \pm SEM values. A $p$ value of $<0.05$ was accepted as a statistically significant difference.

\section{Results}

The effect of paraquat poisoning on HSP70 expression in rat liver was first examined using immunohistochemical technique. As shown in Fig. 1, the expression of HSP70 immunoreactivity in rat liver was observed at $24 \mathrm{hr}$ after the administration of paraquat, and this expression was enhanced in a dose-dependent manner. The positive staining of HSP70 was already apparent by $25 \mathrm{mg} / \mathrm{kg}$, and the spreading of immunostaining from the central to the peripheral area of hepatic lobules was observed according to increasing the dose of paraquat (a-d in Fig. 1). In addition, the immunoreactivity of ubiquitin,

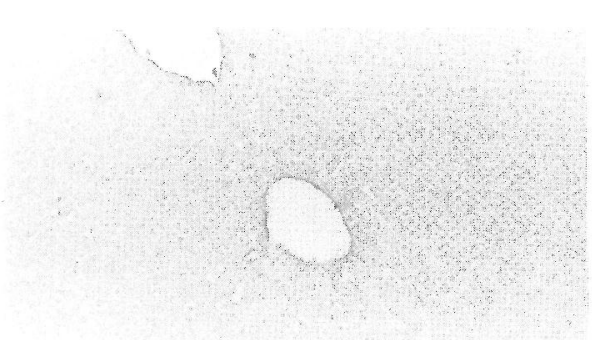

a
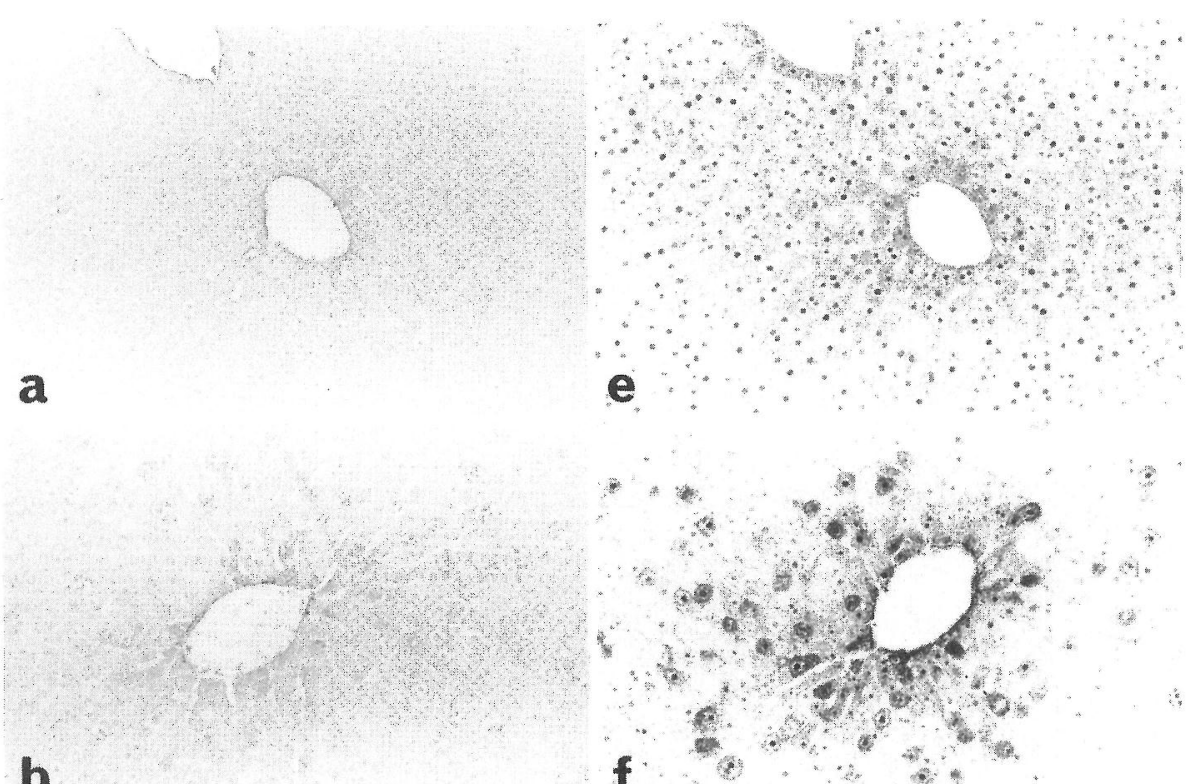

e

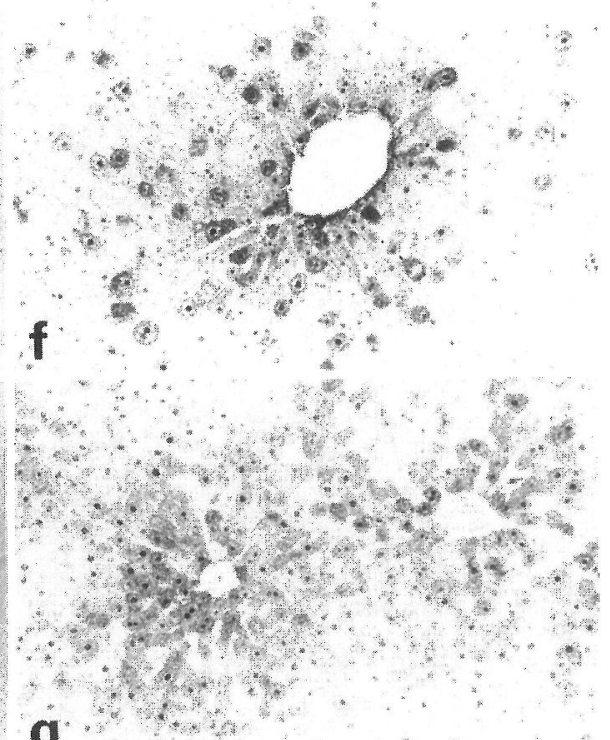

c
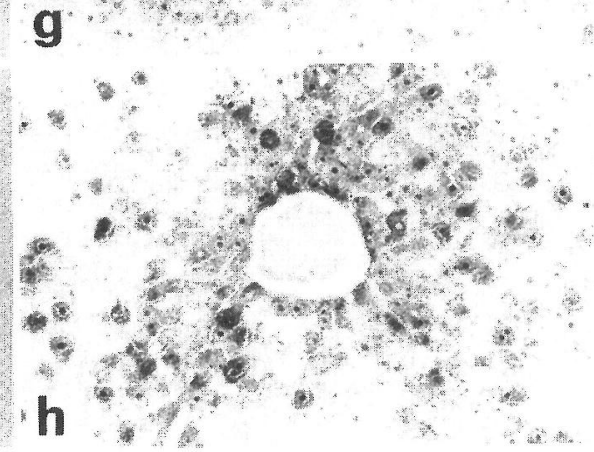

Fig. 1. Expression of HSP70 and ubiquitin immunoreactivities in paraquat-poisoned rat liver. Sections were prepared from the animals treated with saline (a, e), or $25(\mathbf{b}, \mathbf{f}), 50(\mathbf{c}, \mathbf{g})$ and $100(\mathbf{d}, \mathbf{h}) \mathrm{mg} / \mathrm{kg}$ of paraquat for $24 \mathrm{hr}$, and HSP70 (a-d) and ubiquitin (e-h) were then stained as described in the text. 


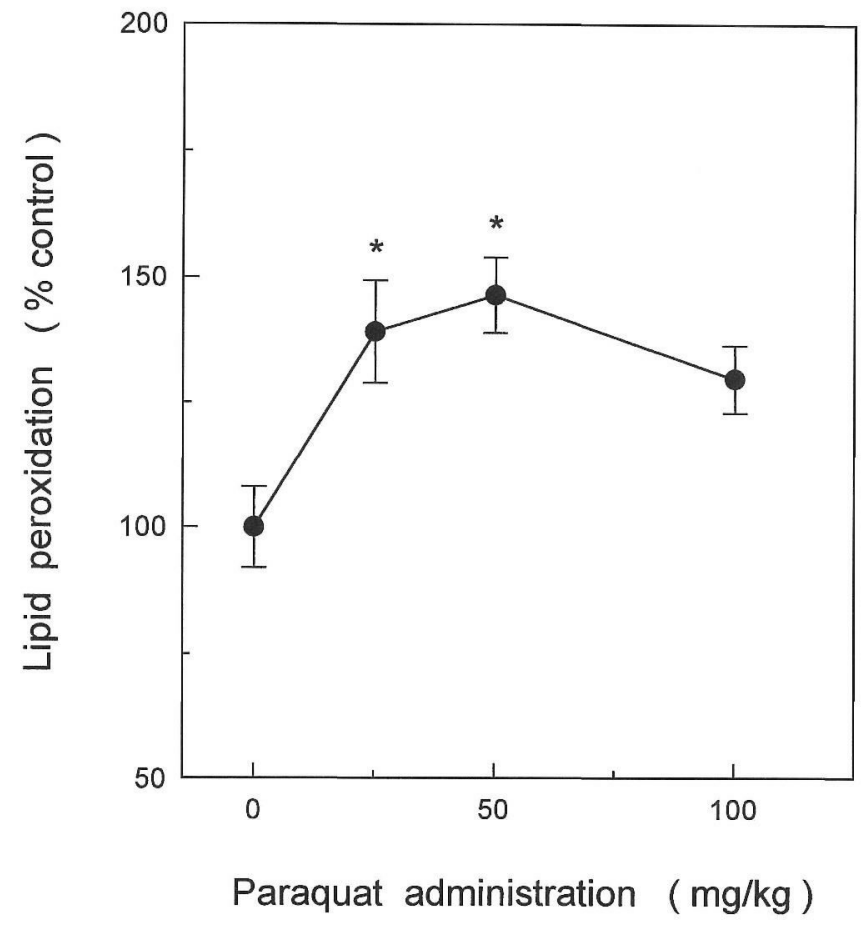

Fig. 2. Lipid peroxidation in paraquat-poisoned rat liver. Animals were treated with various doses of paraquat for $24 \mathrm{hr}$, and lipid peroxidation in the liver was then determined as described in the text. Results were expressed as the percent of control value $(0.31 \pm 0.04 \mu \mathrm{moles} / \mathrm{g}$ of tissue wet weight). Values are the mean \pm S.E. $(n=6) .{ }^{*} p<0.05$

the smallest molecule among HSP family and used as another marker of cell damage, was expressed in rat liver, and, similar to HSP70, this expression was also enhanced by paraquat poisoning (e-h in Fig. 1). These observations seemed to propose the possibility that HSP70 expression was probably associated with the paraquat-induced damage to liver cells.

Since paraquat is well known to cause oxidative damage to various tissues including liver, the effect of paraquat on lipid peroxidation in rat liver was examined to further investigate whether HSP70 expression might be the result of paraquat-induced damage to liver cells. As shown in Fig. 2, lipid peroxidation in rat liver was stimulated by paraquat, and this elevation was still observed at $24 \mathrm{hr}$ after the drug administration. Therefore, it seemed likely that HSP70 expression observed in paraquatpoisoned rat liver might reflect the oxidative damage to liver cells.

To address the question of whether HSP70 expression observed in paraquat-poisoned rat liver was accompanied by its gene expression, the effect of paraquat poisoning on HSP70 mRNA levels in rat liver was examined using a rapid and sensitive one-step RT-PCR method. First, to validate this technique for measurement of HSP70 mRNA, the different amounts of total RNA prepared from rat liver were subjected to the one-step RT-PCR assay. As shown in Fig. 3, two bands were observed
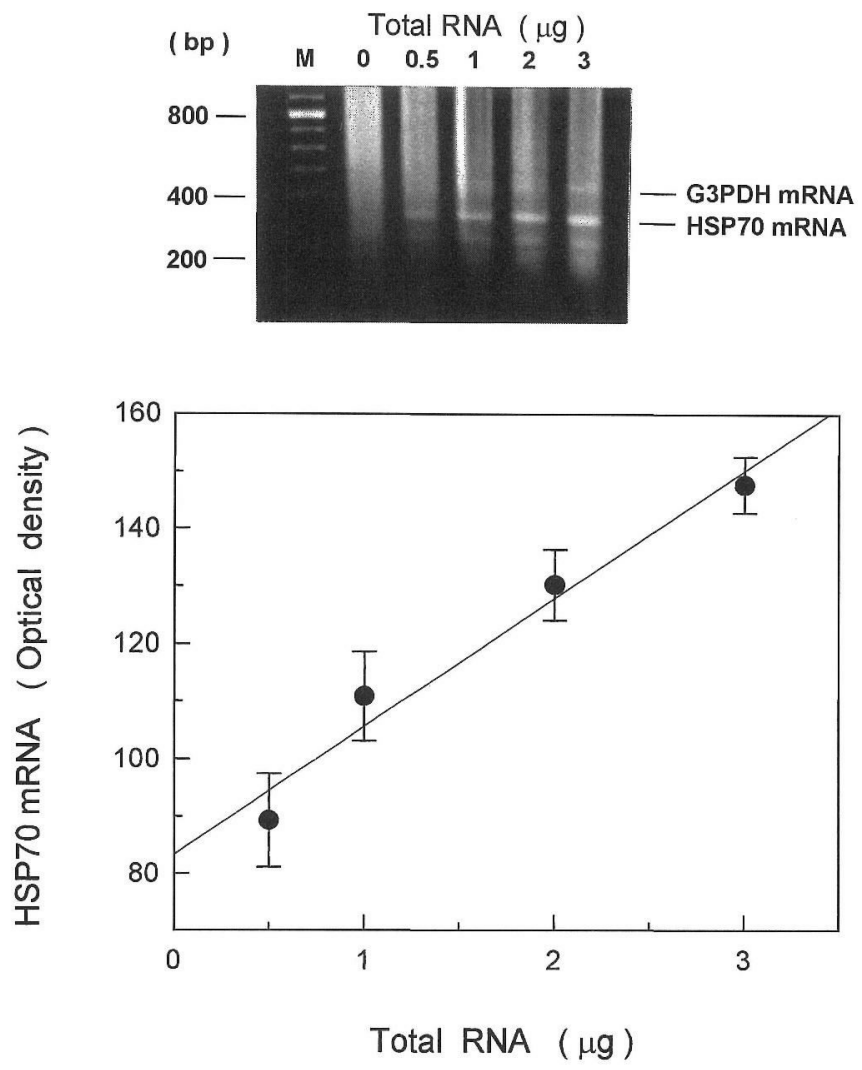

Fig. 3. Sensitivity of one-step RT-PCR method for measurement of HSP70 mRNA levels. Various amounts of total RNA $(0-3 \mu \mathrm{g})$ prepared from rat liver were reverse transcribed and amplified as described in the text. The PCR products were separated by agarose-gel electrophoresis, and the optical densities of bands corresponding to HSP70 mRNA were then determined. Values are the mean \pm S.E. $(n=3)$.

corresponding to the expected size of PCR products for HSP70 mRNA (320 bp) and G3PDH mRNA (452 bp), and the intensity of HSP70 band increased with increasing amounts of total RNA. The densitometric analysis showed that the expression of HSP70 mRNA was easily detected using approximately $0.5 \mu \mathrm{g}$ of total RNA, thus indicating that this one-step RT-PCR assay is sufficiently sensitive to determine HSP70 mRNA expression in rat liver. To investigate the direct association of the appearance of HSP70 immunoreactivity and its gene expression, HSP70 mRNA levels in paraquat-poisoned rat liver were measured. As shown in Fig. 4, paraquat failed to cause any significant effect on HSP70 mRNA levels at $24 \mathrm{hr}$ after the drug administration, even though the expression of HSP70 immunoreactivity was evidently observed under the same conditions. These results seemed to indicate that HSP70 expression observed in paraquat-poisoned rat liver might not be accompanied by the elevation of HSP7 gene expression. 

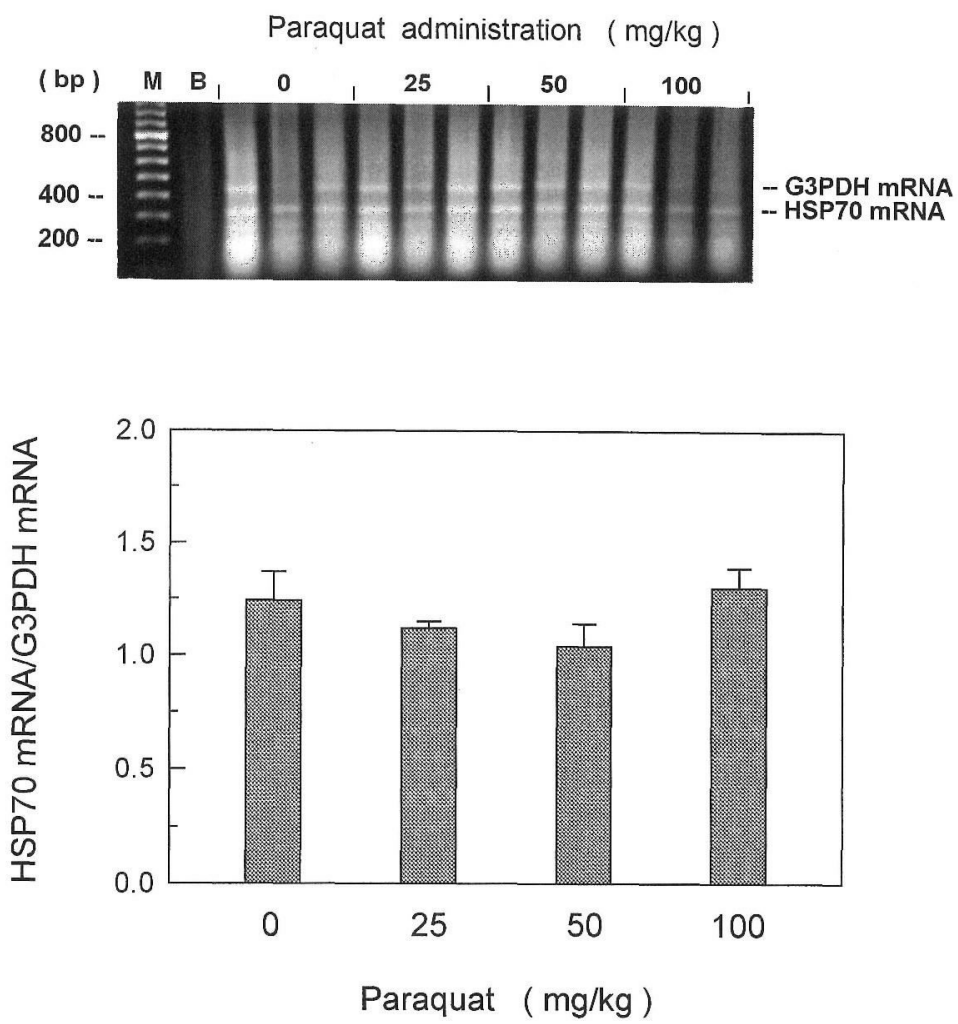

Fig. 4. HSP70 mRNA expression in paraquat-poisoned rat liver. Total RNA ( $2 \mu \mathrm{g})$ prepared from paraquat-treated rat liver was reverse transcribed and amplified, and the PCR products were then separated by agarose-gel electrophoresis as described in the text. The $100 \mathrm{bp}$ DNA mixture was run on the gel as a size marker (lane M), and the reaction without target RNA served as a blank (lane B). The optical densities of two bands corresponding to HSP70 and G3PDH mRNAs were determined, and the results were then expressed as the ratio of HSP70 mRNA levels to G3PDH mRNA levels. Values are the mean \pm S.E. $(n=6)$.

\section{Discussion}

The expression of HSP70 immunoreactivity is generally appreciated as a histological marker of cell damage in various cells and tissues [4, 5, 12, 15]. However, since paraquat-induced HSP70 expression in the senescence-accelerated mouse liver has recently been shown to return to the basal level within $18 \mathrm{hr}$ after the drug administration [10], it seems still possible that the elevation of HSP70 expression is not always detectable in the cells receiving the damage. In contrast, the present studies showed that the expression of HSP70 immunoreactivity in paraquatpoisoned rat liver was observed even at $24 \mathrm{hr}$ after the drug administration (Fig. 1), and also suggested that this expression might be the result of the paraquat-induced oxidative damage to liver cells (Figs. 1, 2), thereby supporting that HSP70 expression is a relevant and useful marker of cell damage for investigating the toxic effect of paraquat on rat liver cells.

The difference in paraquat-induced HSP70 expression between mouse and rat liver seems interesting, but it still remains entirely in question. As a possible mechanism, we hypothesized that the stimulatory effect of paraquat on HSP70 gene expression may be more persistent or HSP70 mRNA may be more stable and lasting in rat liver than in mouse liver. To address this question, the steady-state levels of HSP70 mRNA in paraquat-poisoned rat liver was determined using a one-step RT-PCR method, which was shown to be sufficiently sensitive to detect changes in the mRNA levels (Fig. 3). Under the conditions leading to the elevation of HSP70 immunoreactive protein in rat liver cells, HSP70 mRNA levels was not significantly affected by paraquat poisoning (Fig. 4), thereby suggesting that neither the persistent stimulation of HSP70 gene expression nor the stabilization of HSP70 mRNA may contribute to the elevation of HSP70 immunoreactivity observed in paraquat-poisoned rat liver. In fact, the elevation of HSP70 levels in patients with systemic lupus erythematosus has recently been shown to be independent of the enhancement of transcriptional gene expression [17]. As one speculative possibility, it therefore seems possible that the stabilities of HSP70 immunoreactive proteins in rat and mouse may be different, and this may be responsible for the species difference in HSP70 expression.

The findings presented in this report indicate that paraquat poisoning results in the expression of HSP70 immunoreactivity in rat liver as a result of the oxidative cell damage, thus providing affirmative evidence for the relevance of HSP70 expression as a marker of paraquatinduced cell damage. 


\section{References}

1. Chomczynski, P. and Sacchi, N.: Single-step method of RNA isolation by acid guanidinium thiocyanate-phenol-chloroform extraction. Anal. Biochem. 162; 156-159, 1987.

2. Cohen, D. M., Wasserman, J. C. and Gullans, S. R.: Immediate early gene and HSP70 expression in hyperosmotic stress in MDCK cells. Am. J. Physiol. 261; C594-C601, 1991.

3. Ding, X. Z., Smallridge, R. C., Galloway, R. J. and Kiang, J. G.: Rapid assay of HSF1 and HSF2 gene expression by RTPCR. Mol. Cell. Biochem. 158; 189-192, 1996.

4. Dunn-Meynell, A. A. and Levin, B. E.: Histological markers of neuronal, axonal and astrocytic changes after lateral rigid impact traumatic brain injury. Brain Res. 761; 25-41, 1997.

5. Gaspary, H., Graham, S. H., Sagar, S. M. and Sharp, F. R.: HSP70 heat shock protein induction following global ischemia in the rat. Mol. Brain Res. 34; 327-332, 1995.

6. Kubo, S., Tokunaga, I., Yamamoto, A. and Morita, K.: Immunohistochemical studies on paraquat-induced damage to neuronal and glial cells in rat hippocampus. Acta Histochem. Cytochem. 32; 373-376, 1999.

7. Longo, F. M., Wang, S., Narasimhan, P., Zhang, J. S., Chen, J., Massa, S. M. and Sharp, F. R.: cDNA cloning and expression of stress-induced rat hsp70 in normal and injured rat brain. J. Neurosci. Res. 36; 325-335, 1993.

8. Lowenstein, D. H., Chan, P. H. and Miles, M. F.: The stress protein response in cultured neurons: Characterization and evidence for a protective role in excitotoxicity. Neuron 7; 1053-1060, 1991.

9. Matz, P., Weinstein, P., States, B., Honkaniemi, J. and Sharp, F. R.: Subarachnoid injections of lysed blood induce the hsp70 stress gene and produce DNA fragmentation in focal areas of the rat brain. Stroke 27; 504-512, 1996.
10. Nakanishi, Y. and Yasumoto, K.: Induction after administrating paraquat of heme oxygenase-1 and heat shock protein 70 in the liver of Senescence-accelerated mice. Biosci. Biotech. Biochem. 61; 1302-1306, 1997.

11. Nowak, T.S. Jr.: Protein synthesis and the heat shock/stress response after ischemia. Cerebrovasc. Brain Metab. Rev. 2; 345-366, 1990.

12. Nowak, T.S. Jr. and Jacewicz, M.: The heat shock/stress response in focal cerebral ischemia. Brain Pathol. 4; 67-76, 1994.

13. Schiaffonati, L. and Tiberio, L.: Gene expression in liver after toxic injury: analysis of heat shock response and oxidative stress-inducible genes. Liver 17; 183-191, 1997.

14. Sharp, F. R., Bergeron, M. and Massa, S. M.: Stress response imaging: decreased protein synthesis correlates with induction of HSP70 heat shock protein in rat brain following focal ischemia, global ischemia and status epilepticus. Soc. Neurosci. Abstr. 21; 512, 1995.

15. Sharp, F. R., Kinouchi, H., Koistinaho, J., Chan, P. H. and Sagar, S. M.: HSP70 heat shock gene regulation during ischemia. Stroke 24 (Suppl.); 172-177, 1993.

16. Tokunaga, I., Kubo, S., Mikasa, H., Suzuki, Y. and Morita, K.: Determination of 8-hydroxy-deoxyguanosine formation in rat organs: Assessment of paraquat-evoked oxidative DNA damage. Biochem. Mol. Biol. Int. 43; 73-77, 1997.

17. Twomey, B. M., Amin, V., Isenberg, D. A. and Latchman, D. S.: Elevated levels of the $70 \mathrm{kD}$ heat shock protein in patients with systemic lupus erythematosus are not dependent on enhanced transcription of the hsp70 gene. Lupus 2; 297301, 1993.

18. Wilbur, K. M., Bernheim, F. and Shapiro, O. W.: The thiobarbituric acid reagent as a test for the oxidation of unsaturated fatty acids by various agents. Arch. Biochem. Biophys. 24; 305-313, 1949. 